\title{
Erratum to: Carbonate diagenetic products and processes from various diagenetic environments in Permian paleokarst reservoirs: a case study of the limestone strata of Maokou formation in Sichuan Basin, South China
}

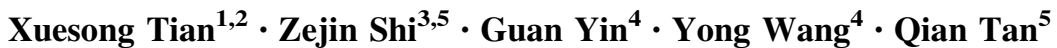

Published online: 6 July 2017

(C) Springer-Verlag GmbH Germany 2017

Erratum to: Carbonates Evaporites (2017)

32:215-230

DOI 10.1007/s13146-016-0296-3

Unfortunately, the original article was published with incorrect scale in Figs. 4, 7 and 8. The figures with corrected scale are displayed here.

The online version of the original article can be found under doi:10.1007/s13146-016-0296-3.

Zejin Shi

zejinshi2016@outlook.com

Xuesong Tian

xuesongtian@outlook.com

1 Nanjing Institute of Geology and Palaeontology, Chinese Academy of Sciences, Nanjing 210008, People's Republic of China

2 University of Chinese Academy of Sciences, Beijing 100049, People's Republic of China

3 State Key Laboratory of Oil and Gas Reservoir Geology and Exploitation, Chengdu University of Technology, Chengdu 610059, People's Republic of China

4 College of Earth Sciences, Chengdu University of Technology, Chengdu 610059, People's Republic of China

5 College of Energy Sciences Resources, Chengdu University of Technology, Chengdu 610059, People's Republic of China 


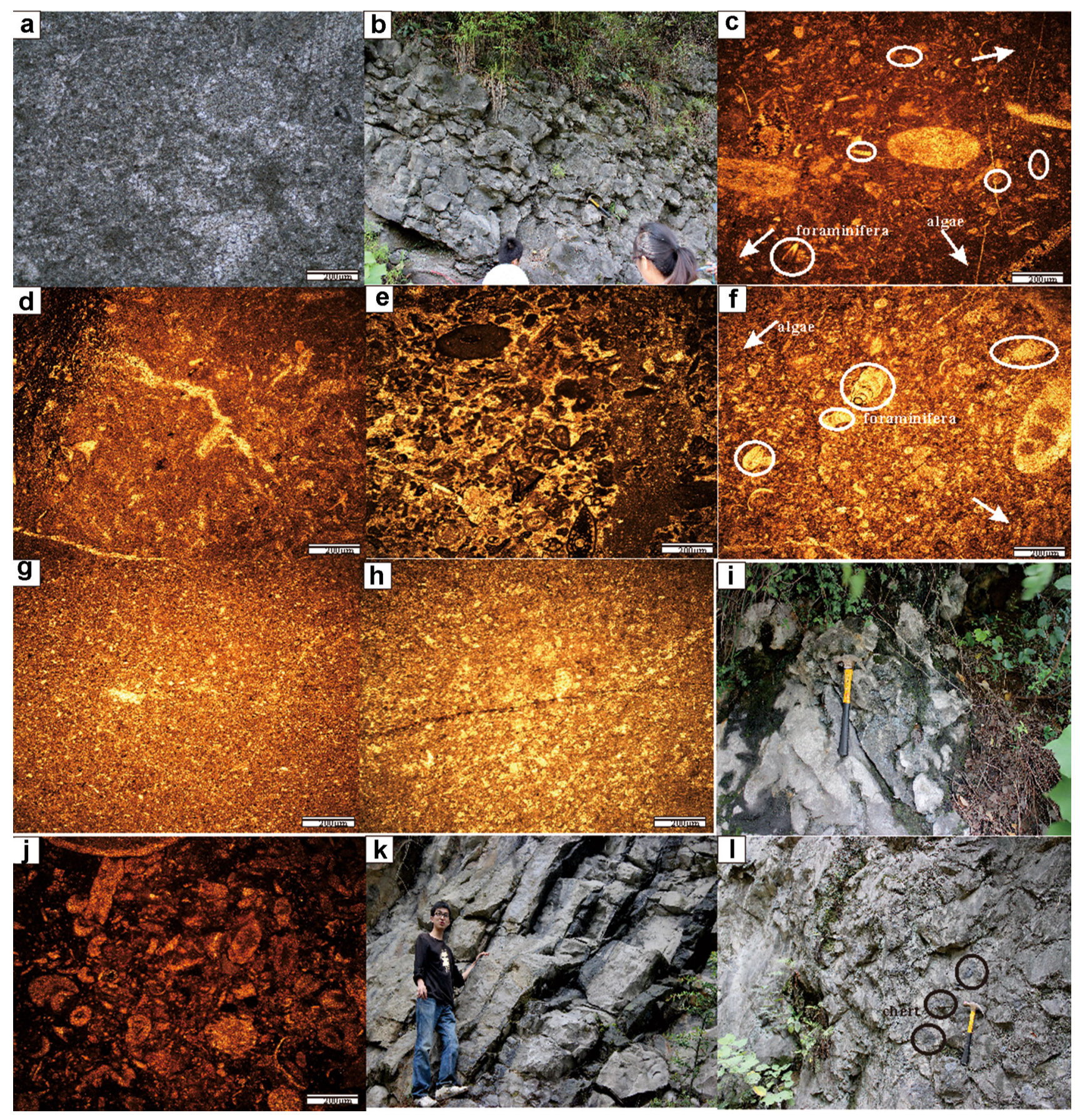

Fig. 4 Main microfacies of marnine carbonate in the Permian Maokou Formation: a micritic limestone with calcite cement, MF-1, Lintanchang section; b micritic limestone with augen structure, MF-1, Zaodu section; c algal and foraminiferous bioclastic micritic limestone, MF-2, Zaodu section; $\mathbf{d}$ algal and foraminiferous bioclastic micritic limestone, MF-2, Gouzishui section; e algal and foraminiferous bioclastic sparitic limestone, MF-3, Taipingdu section; $\mathbf{f}$ algal and foraminiferous bioclastic sparitic limestone, MF-3, Lengshuixi section; g powercrystal limestone, Mf-4, Zaodu section; h powercrystal limestone, MF-4, Shuijiang section; i Karst breccias, MF-5, Shuijiang section; j Sparitic arenite limestone, MF-5, Zaodu section; $\mathbf{k}$ banded chert, Lengshuixi section; I nodule chert, Zaodu section 


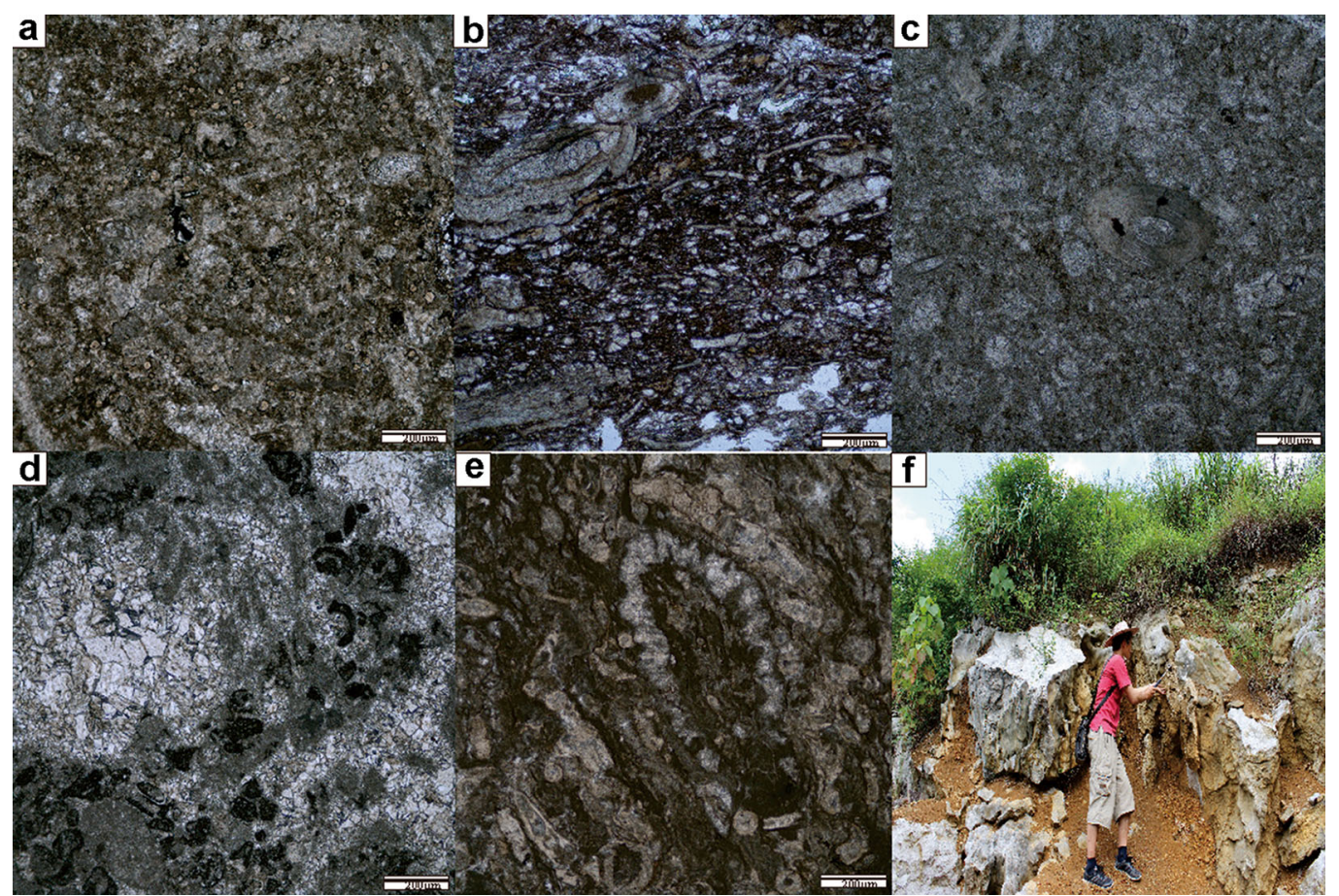

Fig. 7 Main diagenetic types of the Maokou Formation in Sichuan Basin: a dolomitization, Zaodu section; b mechanical and chemical compaction or press-solution, Lintanchang section; $\mathbf{c}$ recrystallization, Shuijiang section; d cementation, containing bladed isopachous and medium-coarse granulous (or patches) calcites, Lintanchang section; e dissolution and later cementation, Gouzishui section; $\mathbf{f}$ dissolution associated with collapse brecciation, Zaodu section. Other details are shown in Fig. 5

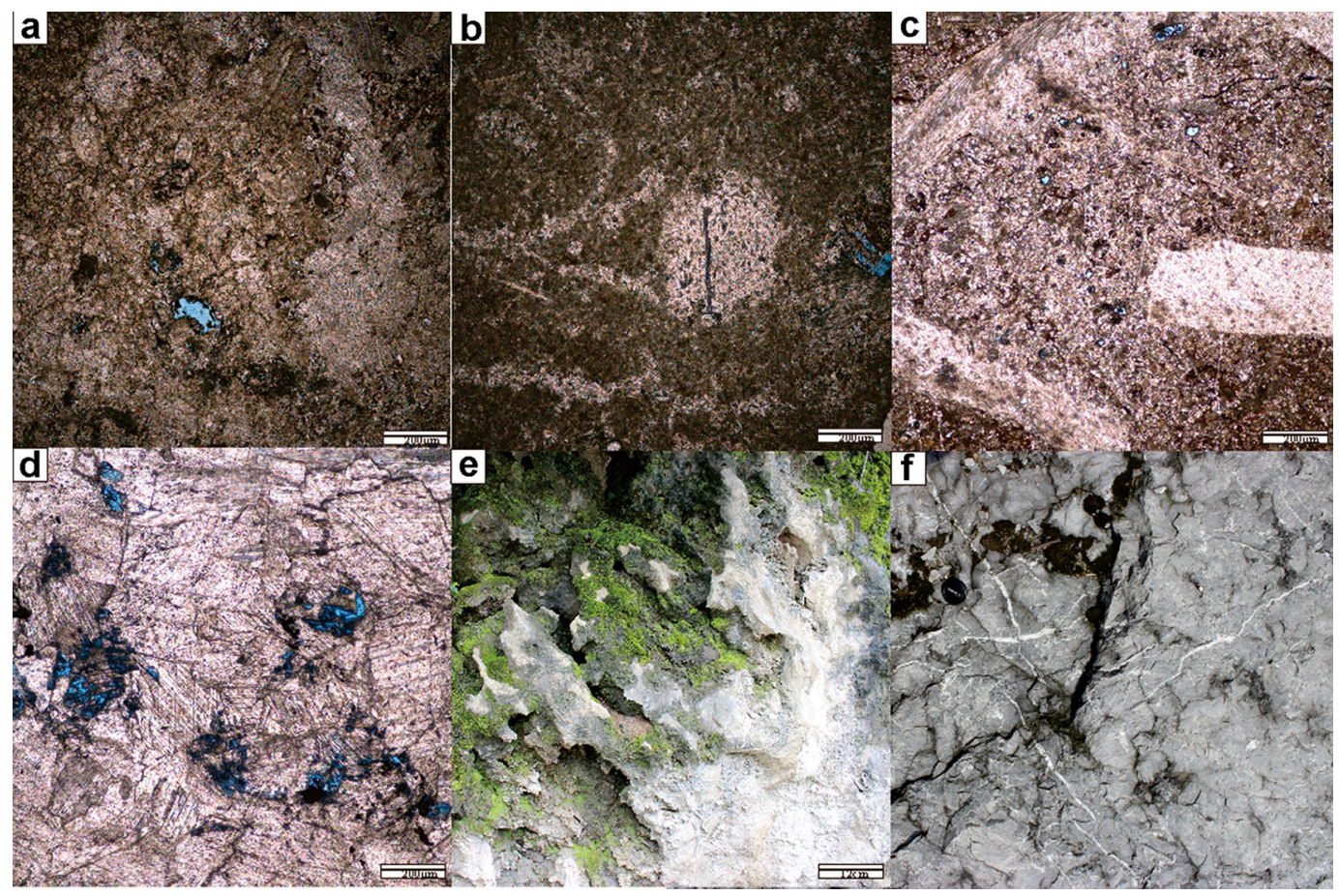

Fig. 8 Main accumulation space of the Maokou paleokarst reservoir in Sichuan Basin: a dissolved inter-grain pore, Taipingdu section; b dissolved intra-grain pore, Shuijiang section; c dissolved pore in the biological body, Gouzishui section; d intercrystalline pore and intercrystalline dissolved pore, Zaodu section; e karst pore-cave, Shuijiang; f fractures, Lintanchang section. Blue casting represents pores with no filling 